\title{
Addendum: Models of Metaplasticity: A Review of Concepts
}

\author{
Pierre Yger ${ }^{1,2 *}$ and Matthieu Gilson ${ }^{3}$ \\ ${ }^{1}$ Sorbonne Université, Université Pierre et Marie Curie Univ Paris06 UMRS968, Paris, France, ${ }^{2}$ Institut de la Vision, Institut \\ National de la Santé et de la Recherche Médicale, U968, Centre National de la Recherche Scientifique, UMR7210, Paris, \\ France, ${ }^{3}$ Computational Neuroscience Group, DTIC, Universitat Pompeu Fabra, Barcelona, Spain
}

Keywords: synaptic plasticity, metaplasticity, Hebbian learning, homeostasis, STDP

\section{An addendum on}

Models of Metaplasticity: A Review of Concepts

by Yger, P., and Gilson, M. (2015). Front. Comput. Neurosci. 9:138. doi: 10.3389/fncom.2015.00138

\section{OPEN ACCESS}

Edited and reviewed by:

Friedemann Zenke,

Stanford University, USA

*Correspondence:

Pierre Yger

pierre.yger@inserm.fr

Received: 26 August 2015 Accepted: 18 December 2015

Published: 28 January 2016

Citation:

Yger $P$ and Gilson M (2016) Addendum: Models of Metaplasticity:

A Review of Concepts. Front. Comput. Neurosci. 10:4 doi: 10.3389/fncom.2016.00004

\section{AUTHOR CONTRIBUTIONS}

All authors listed, have made substantial, direct and intellectual contribution to the work, and approved it for publication.

\section{ACKNOWLEDGMENTS}

MG acknowledges funding from FP7 FET ICT Flagship Human Brain Project (604102).

Conflict of Interest Statement: The authors declare that the research was conducted in the absence of any commercial or financial relationships that could be construed as a potential conflict of interest.

Copyright (c) 2016 Yger and Gilson. This is an open-access article distributed under the terms of the Creative Commons Attribution License (CC BY). The use, distribution or reproduction in other forums is permitted, provided the original author(s) or licensor are credited and that the original publication in this journal is cited, in accordance with accepted academic practice. No use, distribution or reproduction is permitted which does not comply with these terms. 